\title{
Complexity-simplicity, symmetry-asymmetry, and sociometric choice ${ }^{1}$
}

\author{
MICHAEL S. GROVE AND RUSSELL EISENMAN ${ }^{2}$ \\ TEMPLE UNIVERSITY
}

In order to study the interrelationships associated with shape preference, 30 undergraduate $S$ s made complexity-simplicity and symmetry-asymmetry choices, and also made sociometric choices of others as well as predicting the sociometric choices of others. Ss who preferred complexity tended to choose $S s$ who preferred symmetry, which was interpreted as complementary choice. Other findings suggest that complexity and asymmetry are not identical, although there is some relationship between the two.

This article represents one of several attempts to understand social and personality variables related to shape preference. Barron (1963) has presented a series of studies that supports the view that preference for complex line drawings is associated with independence, openness to experience, and other variables related to creativity, while preference for simpler line drawings is associated with a more inhibited noncreative personal style. Eisenman (1968c) has summarized much of his earlier research on complexity-simplicity preferences for polygons of varying degrees of complexity. The research tends to support Barron's view that complexity-simplicity preference reflects different personality styles. In addition, Taylor and Eisenman (1964) found that art students rated as creative preferred more complexity than did their less creative peers, and Eisenman (1969) found that complexity was significantly related to more originality and fluency in a modified unusual-uses test. Eisenman and Robinson (1967) also found complexity preference related to a personality measure of creativity. These findings are consistent with Barron's notions about complexity-simplicity preferences and creativity. Eisenman (1968a), while not obtaining support for Barron's position, found that complexity-simplicity preferences for polygons were not related to Scholastic Aptitude Test scores, which is consistent with a view that complexity-simplicity preferences are not merely reflections of intellectual differences. In sum, the research that has attempted to expand the findings of Barron has suggested that preference for complexity in polygons is associated with a more creative personality style, and preference for simplicity would seem to be associated with less original or creative abilities.

The present study was undertaken to study further variables relating to complexity-simplicity preferences. Specifically, it was deemed desirable to know if Ss who preferred, say, complexity in polygons, would also make sociometric choices of other Ss who likewise preferred complexity. Byme (1961) found that interpersonal attraction was related to attitude similarity. Based on Byrne's finding, we might expect $S s$ who preferred complexity to choose other $S$ s who preferred complexity, since these Ss would have similar outlooks (Barron, 1963; Eisenman, 1968b, c). However, it is quite possible that preferences for complexity have no relationship to sociometric choice, or that a complementary relationship exists. Complementary relationships might most frequently be relevant in mate selection, where, e.g., a dominant person might choose a submissive mate (Byme, 1966). Second, the question of accuracy comes into question. Since preference for complexity can, at least by analogy, be related to cognitive complexity (Eisenman, $1968 \mathrm{~b}$ ), it would be predicted that Ss who preferred complexity would be more accurate in describing the sociometric choice of others, due to more accurate social perception in Ss who preferred complexity. Third, is popularity, as indicated by sociometric choice from others, related to shape preference? It is not clear if complexity, simplicity, symmetry, or any of these variables should be associated with popularity, and the present study was designed to consider this question, as well as to examine other variables, such as grade point average, which might correlate with popularity. Finally, the present design allowed us to study the correlates of complexity-simplicity preference, to see if preference for complexity would be associated with dislike of symmetry, as Barron (1963) would suggest, or if symmetry has some less obvious relationship to complexity preference.

\section{METHOD}

Subjects

The Ss were 30 Temple University students meeting regularly in scheduled small groups twice a week for a semester, as part of a Group Dynamics course requirement. There were 23 females and 7 males.

\section{Stimulus Material}

A photograph of 12 polygons was presented to each $\mathrm{S}$. There were three each of 4-, 12-, and 24-point shapes taken from Vanderplas and Garvin (1959) and one each of 4-, 8-, and 10-point shapes taken from Birkhoff (1933). The Vanderplas and Garvin shapes were originally randomly constructed by connecting random points on a 100 by 100 grid, and are asymmetrical. The Birkhoff shapes are symmetrical.

Procedure

All Ss were asked to choose the three polygons they liked best and the three they liked least. Then they listed their grade-point average and chose the two group members they would want to be with the most. All Ss then listed whom they thought those two people had selected.

The total number of points of the three polygons liked best and least were calculated, along with a preference for symmetry score, based on the number of symmetrical polygons liked best and liked least. The Ss were categorized as (1) preferring simplicity, (2) not clearly preferring either simplicity or complexity, or (3) preferring complexity. Sociograms were made for each group.

\section{RESULTS AND DISCUSSION}

If Barron's complexity-simplicity difference is in fact a personality dimension, then we might expect to find a tendency for complexity-preferring $S s$ to prefer other complexity-preferring Ss over simplicity-preferring $\mathrm{Ss}$, and vice versa, as well as symmetry-preferring Ss preferring others preferring symmetry more often than symmetry-disliking persons. This would be hypothesized from much of the literature in social psychology presenting instances, with the notable exception of marriage, where people prefer others like themselves rather than people who are their complement. Perhaps the most surprising finding of this study is that Ss preferring complex polygons preferred both people who liked simple polygons over complex ones and people who liked symmetrical rather than asymmetrical polygons. 
Table 1

Intercorrelations of All Variables

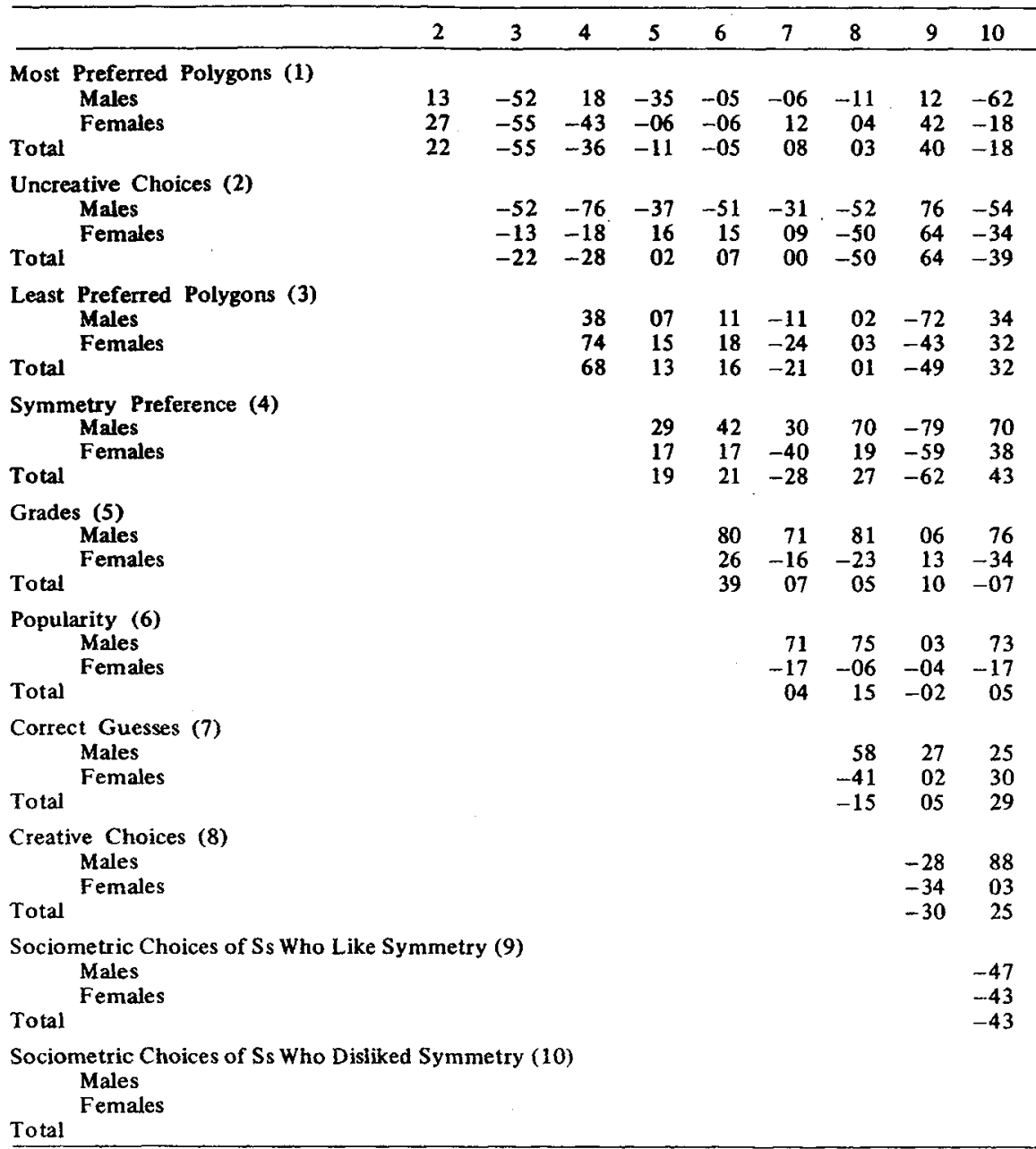

Note-Decimals have been omitted. For males .05 level is $r=.754, .01$ level is $r=.874 ;$ for females .05 level is $r=.423, .01$ level is $r=.537$; for the total sample .05 level is $r=.361, .01$ level is $r=.463$.

This was determined by a $t$ test of complexity-preferring and simplicity-preferring groups. All Ss were categorized as (1) preferring simplicity, (2) not clearly preferring either simplicity or complexity, and (3) preferring complexity. Ss were classified as complexity preferers, simplicity preferers, or those who did not clearly prefer either simplicity or complexity. Complexity preferers were those who had a point total of polygons liked best equal to or greater than the point totals of one complex polygon and two intermediate polygons. The point total of the three polygons disliked, for complexity preferers, had to be less than the point total of the three intermediate polygons. That is, for complexity preferers, the mean point total of polygons preferred had to be greater than that of the intermediate-level polygons and the disliked total had to be less than the intermediate polygon level, showing that $\mathrm{S}$ truly preferred complexity consistently in his choices, and was not placed in the complexity-preferring group because of an idiosyncratic preference for one complex figure. Similarly, simplicity preferers had point totals of polygons liked best under the intermediate polygon level and had disliked point total above the intermediate polygon level. Symmetry preference was not taken into account in the categorizing of $S$ as complexity preferring, simplicity preferring, or not clearly preferring either. The $t$ tests were based on two groups: Group 3 , complexity preferers, $\mathrm{N}=7$, and Group 1 , simplicity preferers, $N=15$. One variable was the number of people chosen who liked simplicity. The Group 3 mean was 1.43 and the Group 1 mean was 0.73 $(t=2.31, p<.05)$. Another variable was number of people chosen who liked symmetry (symmetry preferers picked at least two out of the three polygons liked best that were symmetrical). The Group 3 mean was 1.29 choices vs 0.47 choices for Group $1(\mathrm{t}=3.52, \mathrm{p}<.01)$. Group 3 was also found to like more complexity ( $p<.01$ of significance), dislike more simplicity $(p<.01)$, and like less symmetry $(p<.05)$ than the Group 1 Ss. There were no significant $t$-test differences between males and females or between more popular and less popular Ss for any of the variables.

A correlation matrix was computed for all Ss $(\mathrm{N}=30)$, for males alone $(\mathrm{N}=7)$, and for females alone $(\mathrm{N}=23)$. Pearson product-moment correlations were used, with the results shown in Table 1.

The amount of complexity preferred, as determined by the number of points on the polygons liked best, was correlated to a dislike of simplicity, .546 (significant at $p<.01$ ) for all Ss and .548 (significant at $\mathbf{p}<.01)$ for females, and a dislike of symmetrical polygons, $.363(\mathrm{p}<.05)$ for all $\mathrm{Ss}$ and $.433(\mathrm{p}<.05)$ for females. These correlations are similar to those found previously in the research of Eisenman, Grove, Coyle, and Reddick (1969), while the absence of significant correlations for males can be explained by the very small $\mathrm{N}$ or by sex differences. The preference for complex polygons was also correlated to the number of people picked who liked symmetry, .395 $(\mathrm{p}<.01)$ for all Ss and $.424 \quad(p<.05)$ for females. Symmetry preferers had to pick at least two symmetrical polygons out of the three they liked best, while symmetry dislikers had to pick two symmetrical polygons out of the three they disliked most. This result, complexity preference linked with a preference for people of an opposite nature preferring symmetry, also found in $t$ tests, should be considered in further research. Perhaps the more open, creative person feels a degree of prestige and lack of threat from the more rigid, less open members in his group. It is also possible that $\mathrm{Ss}$ in small groups, when selecting personal preferences, seek a kind of balance (or complement) in their group. In any case, the findings about $\mathbf{S}$ choices in small groups cannot be generalized to apply to mean that all complexity-preferring Ss tend to prefer symmetry-preferring people in all situations. Further research is needed to determine which situational factors affect this preference.

A dislike of complex polygons was correlated with preference for symmetrical polygons, $.681(\mathrm{p}<.01)$ for all Ss and .742 $(p<.01)$ for females, and correlated with preference for people who dislike symmetry, $.487(p<.01)$ for all Ss and $.424(p<.05)$ for females. These correlations are in opposite direction of those with preference for complexity, as is to be expected. 
Preference for symmetrical polygons was correlated with preference for people disliking simplicity, $.759(\mathrm{p}<.05)$ for males, and correlated with preference not to choose people who like symmetry, .621 $(p<.01)$ for all Ss, .795 $(p<.05)$ for males, and .591 ( $\mathrm{p}<.01)$ for females, and correlated with preference for people who dislike symmetry, .430 ( $p<.05)$ for all Ss.

Ss' cumulative grade-point average was correlated with preference for people liking complexity, .814 $(p<.05)$ for males, and preferring people who dislike symmetry, $.762(\mathrm{p}<.05)$ for males, and with the number of times preferred by other group members, $.389(\mathrm{p}<.05)$ for all Ss and .800 $(p<.05)$ for males. The lack of significant correlations for females with grades suggests that grades may be indicative of personality factors related to complexity-simplicity preference in males, while a result of entirely different personality factors for females. Previous research by Eisenman (1968a) has shown preference for polygons unrelated to a measure of intelligence (Scholastic Aptitude Test scores), so correlations between grades and preferences cannot be explained by saying that Ss like the more intelligent members of the group.

The accuracy of predicting the preference of those people the $\mathrm{S}$ most preferred was not related to any shape preferences, popularity, or grade average. This aspect of social insight clearly is an independent factor.

The preference for people who disliked symmetry was correlated with preference for people who liked complexity, .881 $(\mathrm{p}<.01)$ for males, and correlated negative with preference for people who liked symmetry, $.429(\mathrm{p}<.05)$ for all Ss and $.425(\mathrm{p}<.05)$ for females.

These findings are consistent with Eisenman and Rappaport (1967) who questioned the tendency of Barron (1963) to equate complexity and asymmetry, on the one hand, and to equate simplicity and symmetry, on the other hand. The present research indicated that Ss who preferred complexity chose Ss who preferred symmetry, while Ss who liked symmetry chose Ss who disliked symmetry. Such a finding can be reconciled with Barron's approach if we introduce the superordinate concept of "complementary choice." It seems that Ss choose persons different from themselves as far as shape preferences are concerned, at least when asked to pick the two people they would most like to be with. Thus, the findings suggest that Eisenman and Rappaport (1967) are correct in suggesting that c omplexity-simplicity and symmetry-asymmetry are somewhat different dimensions, but that Barron (1963) is not entirely wrong in thinking that, to some extent, complexity preference is associated with dislike of symmetry $(r=-.363, p<.05$ in the present study). Recent findings by Rump $(1968 a, b)$ suggest that shape preference is not easily explained by the phrase "preference for complexity" unless other aspects are spelled out. The present findings and the research by Eisenman and Rappaport (1967) support the belief that the investigator of complexity preferences should consider such variables as symmetry in analyzing his findings. Further, the "obvious" belief that Ss who preferred complexity would choose other Ss who munired complexity if they had to be with someone was not supported, since the findings were significant in the opposite direction, indicating complementary choice. Together, the findings of this study and related investigations of shape preference suggest the complexity of the whole area and the need to avoid untested generalizations.

\section{REFERENCES}

BARRON, F. Creativity and psychological health. Princeton: Van Nostrand, 1963.

BIRKHOFF, G. D. Aesthetic measure. Cambridge: Harvard University Press, 1933.

BYRNE, D. Interpersonal attraction and attitude similarity. Journal of Abnormal \& Social Psychology, 1961, 62, 713-715.

BYRNE, D. An introduction to personality. Englewood Cliffs, N.J: Prentice-Hall, 1966.
EISENMAN, $R$. Birth order, insolence, socialization, intelligence, and complexity-simplicity preferences. Journal of General Psychology, 1968a, 78, 61-64.

EISENMAN, R. Complexity-simplicity and reaction to threatening information. Journal of Consulting \& Clinical Psychology, 1968b, 32, 638-641.

EISENMAN, $R$. Values and attitudes in adolescence. In J. F. Adams (Ed.), Understanding adolescence. Boston: Allyn \& Bacon, 1968c. Pp. 183-197.

EISENMAN, R. Creativity, awareness, and liking. Journal of Consulting \& Clinical Psychology, $1969,33,157-160$.

EISENMAN, R., GROVE, M., COYLE, F. A., JR., \& REDICK. Studies in complexitysimplicity: I. Children's preferences, and II. Personality correlates in college students. Proceedings of the 77 th Annual Convention of the American Psychological Association, 1969, 4, 473-474.

EISENMAN, R., \& RAPPAPORT, J. Complexity preference and semantic differential ratings of complexity-simplicity and symmetry-asymmetry. Psychonomic Science, $1967,7,147-148$.

EISENMAN, R., \& ROBINSON, N Complexity-simplicity, creativity, intelligence, and other correlates. Journal of Psychology, $1967,67,331-334$.

RUMP, E. E. Is there a general factor of preference for complexity? Perception \& Psychophy sics, 1968a, 3, 346-348.

RUMP, E. E. Relative preference as a function of the number of elements in abstract designs. Australian Journal of Psychology, 1968b, 20, 39-48.

TAYLOR, R. E., \& EISEnMan, R. Perception and production of complexity by creative art students. Journal of Psychology, 1964, 57, 239-242.

VANDERPLAS, J. M., \& GARVIN, E. A. The association value of random shapes. Journal of Experimental Psychology, 1959, 57, 147-154.

\section{NOTES}

1. This research was supported by a grant from the Trustees of Temple University to the second author. The authors are grateful to Dr. M. Gershenfeld for allowing us to test her class and to the Temple University Computer Center for their assistance.

2. Address: Department of Psychology, Temple University, Philadelphia, Pennsylvania 19122.

(Accepted for publication February 9, 197a) 